\title{
Health vigilance concerning female urinary tract infections: Epidemiological profile and antibiotic resistance
}

\author{
SoumaiaFarih ${ }^{l, *} \quad$ AbderrazakSaddari ${ }^{l}, \quad$ BenhamzaNoussaiba ${ }^{l}, \quad$ AdnaneAraab $^{l}, \quad$ LoubnaYacoubi $^{l}$, \\ ElmostaphaBenaissa ${ }^{3,4}$, Yassine Ben Lahlou ${ }^{3,4}$, Adil Maleb ${ }^{1,2}$ and Mostafa Elouennass ${ }^{3,4}$. \\ ${ }^{1}$ Laboratory of Microbiology, Mohamed VI teaching hospital/ Faculty of Medicine and Pharmacy (University Mohammed the \\ first), Oujda, Morocco.
}

${ }^{2}$ Research team "Cell Biology and Pharmacology Applied to Health Sciences". Faculty of Medicine and Pharmacy (University Mohammed the first), Oujda, Morocco.

${ }^{3}$ Department of Bacteriology, Mohammed V Teaching Military Hospital, Rabat, Morocco.

${ }^{4}$ Epidemiology and bacterial resistance research team/BIO-INOVA Centre, Faculty of Medicine and Pharmacy (University Mohammed V), Rabat, Morocco

\begin{abstract}
The objectives of our work were to establish the epidemiological and bacteriological profile of female urinary tract infection at the Mohammed VI University Hospital of Oujda (Morocco), and then to study the drug resistance of the bacterial strains isolated. This is a retrospective study over 36 months including urine samples from patients hospitalized or consulting at the CHU Mohamed VI of Oujda (Morocco). Urines were processed according to the recommendations of the Medical Microbiology Reference (REMIC) and the EUCAST (European Committee on Antimicrobial Susceptibility Testing).

We collected 12556 requests for CBEU from different departments. At the top of the list was the emergency department with a rate of $37 \%(n=4666)$ followed by outpatient clinics $(33.1 \%$; $n=4226) .5 \%(n=630)$ of the CBEU were positive. Escherichia coli (E. coli ) dominated the epidemiological profile with a rate of $72.50 \%(n=482)$. E. coli was resistant to penicillins in $69.50 \%(\mathrm{n}=299)$ of cases, protected penicillins in $34.80 \% \quad(\mathrm{n}=149)$, third generation cephalosporins $(\mathrm{C} 3 \mathrm{G})$ in $9 \%(\mathrm{n}=38)$, fluoroquinolones in $17.5 \%(\mathrm{n}=73)$, TrimethoprimSulfamethoxazole in $46 \%(n=196)$ of cases and gentamicin in $12 \%(n=51)$ of cases. None of the strains were resistant to carbapenems.

Awareness-raising on the proper use of antibiotics, issuing national recommendations for the treatment of urinary tract infections in order to standardize therapeutic regimens. Effective control of these infections requires a global prevention strategy that implies close collaboration between epidemiologists, clinicians, bacteriologists, hygienists and the health care team.
\end{abstract}

\section{Background:}

Urinary tract infection (UTI) is one of the most common community-acquired infections, and is the second most common site of bacterial infection after the respiratory tract in both adults and children. It is the leading cause of healthcare-associated infections. Urinary tract infection corresponds to the aggression of a tissue of the urinary tract by one or more germs, generating an inflammatory response and clinical symptoms of variable nature and intensity depending on the terrain and the existence or not of a functional anomaly of the urinary tract, which can lead to serious clinical pictures. Colonization corresponds to the presence of one or more microorganisms in the urinary tract without clinical manifestation and does not require treatment except in specific conditions. [1] It is pathology of variable severity that requires rapid and effective management. The incidence of UTI in women increases with age, with two peaks, one at the beginning of sexual activity and the other in the post-menopausal period. Often considered to be trivial, UTI can become complicated and lead to severe consequences [2].

The main objectives of our study are to establish the epidemiological and bacteriological profile of female urinary tract infection at the Mohammed VI University Hospital of Oujda (Morocco)and then to study drug resistance of bacterial strains isolated.

\section{Materials and methods:}

This is a 36 months retrospective study from March 22, 2016 to April 11, 2019. The study included urinary specimens of patients admitted to the various departments of the Mohamed VI University Hospital 
of Oujda sent to the microbiology laboratory of the Mohammed VI University Hospital of Oujda for cytobacteriological examination. The CBEU requests were prescribed on the hospital information system (HOSIX, SIVSA SolucionesInformáticas). The prescribers were required to fill in a questionnaire with clinical information useful for the interpretation of the UEC results. The urine samples and the prescription sheets were sent to the laboratory through the pneumatic system, within a maximum of 30 minutes and at room temperature. Storage of the urine samples (boric acid, ice. . .) was not necessary, as UEC was possible in our laboratory 24 hours a day, seven days a week. In the laboratory, as soon as the urine samples were received, the technicians checked that they complied with the requirements of the medical microbiology standard. of the medical microbiology standard. These noncompliances concerned the bottle containing the urine sample (damaged, unidentified. . .), the urine sample (missing, visibly contaminated, taken from a collection bag from a probed patient. .), or the prescription sheet for the CBEU (missing, wrong identity. . .). Depending on the non-conformities observed, the CBEU was rejected, performed subject to the non-conformity found or kept in the laboratory pending correction of the non-conformity within 30 minutes of receipt of the urine sample. In all cases, a report of the non-conformity was sent to the CBEU prescriber through the laboratory's computer system (iLAB, SIVSA SolucionesInformáticas).Noncompliant urinary samples (visibly contaminated, sent to the laboratory more than two hours after collection, or contained in a bottle of urine) were sent to the laboratory through the $\mathrm{iLAB}$ system. .) and duplicates were excluded from our study. Compliant

\section{Results:}

During the study period, we collected 23215 UBEC requests, of which 12556 were women (54\%) with a mean age of 37.55 years.

Cultures were sterile in $48 \%(n=6009)$ of cases, positive for urinary colonization in $6 \%(\mathrm{n}=714)$ of cases, and positive for urinary tract infection in $5 \%(n=630)$ of cases. Cultures were polymorphic (contaminated urine) in $41 \%(n=5168)$ of cases (Figure1). The emergency department was the first requestor of ECBU with a rate of $37 \%(\mathrm{n}=4666)$ followed by outpatient clinics $(33.1 \%$; $\mathrm{n}$ $=4226$ ). Urinary colonization is marked by the predominance of the senile population with an age of $(66.5 \% \mathrm{n}=488)$, while the (pediatric and young) population represents $(33.5 \% \mathrm{n}=246$.) with an average age $=52$ years. For all the patients studied, $1 \%$ were pregnant $(\mathrm{n}=8)$ and $1 \%$ had a scheduled invasive urological procedure $(n=8)$, while the majority $(98 \%)(n=698)$ had no situation justifying urinary decolonization. For bacterial species, E. coli $(n=493$; urine was processed, without delay, in accordance with the recommendations of the medical microbiology guidelines (REMIC)[1]. in force during the period of our study period.[1] noculation was carried out on UTI Brillance Agar (Oxoid TM). Incubation of the culture dishes lasted 24 to 48 hours in aerobic conditions at $37^{\circ} \mathrm{C}$. Immediately after plating, urine cytology was determined on the UF1000 i (Sysmex), which was used to quantify, among other things, leukocytes and red blood cells per millilitre of urine. The significant threshold for leukocyturia was $\geq 104 / \mathrm{ml}$. After the incubation time of the culture media had elapsed (24-48 hours), urine was considered contaminated if there was a polymorphic culture of at least three different germ types with a count of $103 \mathrm{CFU} / \mathrm{mL}$ or more. The identification of the contaminating germs and the study of their sensitivity to antibiotics were not carried out. Cultures positive for one or two germs were compared with cytology results and clinical information to distinguish between urinary tract infection and urinary colonisation. The identification of isolated bacteria was carried out using the BD PhoenixTM 100 (Becton Dickinson).

Antibiotic susceptibility testing was carried out in accordance with the recommendations of the French Microbiology Society's Committee on Antibiotic susceptibility Testing (CA-SFM) and the European Committee on Antimicrobial Susceptibility Testing (EUCAST) [3]. The results were interpreted in accordance with the recommendations of the REMIC (référentielenmicrobiologiemédicale)[1].

Urine dipstick screening for UTI and testing for Mycobacteria in renal tuberculosis were not performed.

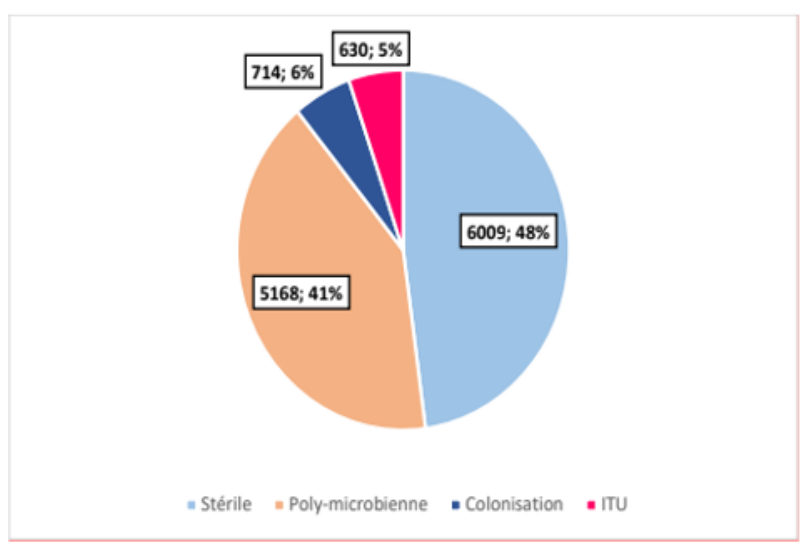

Figure 1 :Distribution of the results of the requested CBEU

$69.6 \%$ ) was the main germ isolated during our study in terms of colonization, followed by Klebsiella pneumonia $(n=102 ; 14.3 \%)$.Concerning urinary tract infections, the age distribution found two populations: a pediatric 
population (age $<15$ years) with a majority of $34 \%$ $(\mathrm{n}=226)$ and a senile population with a peak of $13.8 \%$ $(n=92)$ between $56-65$ years. The average age $=37.52$ years. The urinary colonization is marked by the predominance of the senile population with an age of $(66.5 \% \mathrm{n}=488)$, while the population (pediatric and young) represents $(33.5 \% \mathrm{n}=246$.) with an average age $=$ 52 years. For all the patients studied, $1 \%$ were pregnant $(n=8)$ and $1 \%$ had a scheduled invasive urological procedure $(n=8)$, while the majority $(98 \%)(n=698)$ had no situation justifying urinary decolonization. For bacterial species, E. coli $(n=493 ; 69.6 \%)$ was the main germ isolated during our study in terms of colonization, followed by Klebsiella pneumonia $(n=102$; $14.3 \%$ ).Concerning urinary tract infections, the age distribution found two populations: a pediatric population (age $<15$ years) with a majority of $34 \%(n=226)$ and a senile population with a peak of $13.8 \%(n=92)$ between $56-65$ years. The average age $=37.52$ years.

$(66.5 \% \mathrm{n}=488)$, while the population (pediatric and young) represents $(33.5 \% \mathrm{n}=246$.) with the average age $=$ 52 years. For all the patients studied, $1 \%$ were pregnant $(\mathrm{n}=8)$ and $1 \%$ had a scheduled invasive urological procedure $(n=8)$, while the majority $(98 \%)(n=698)$ had no situation justifying urinary decolonization. For bacterial species, E. coli $(n=493 ; 69.6 \%)$ was the main germ isolated during our study in terms of colonization, followed by Klebsiella pneumonia ( $\mathrm{n}=102$; $14.3 \%$ ).Concerning urinary tract infections, the age distribution found two populations: a pediatric population (age $<15$ years) with a majority of $34 \%(n=226)$ and a senile population with a peak of $13.8 \%(n=92)$ between $56-65$ years. The average age $=37.52$ years.

Escherichia coli dominated the epidemiological profile with a rate of $72.50 \%(n=482)$. E. coli was resistant to penicillins in $69.50 \%(\mathrm{n}=299)$ of cases, protected penicillins in $34.80 \% \quad(n=149)$, third generation cephalosporins $(\mathrm{C} 3 \mathrm{G})$ in $9 \%(\mathrm{n}=38)$, fluoroquinolones in $17.5 \%(\mathrm{n}=73)$, Trimethoprim-Sulfamethoxazole in $46 \%$ $(n=196)$ of cases, and gentamicin in $12 \%(n=51)$ of cases. No strain was resistant to carbapen

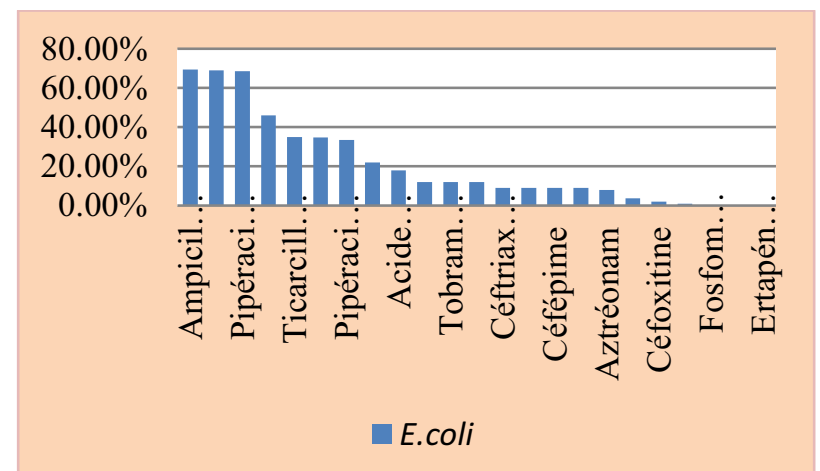

Figure 2: Resistance of isolated Escherichia coli to isolated to antibiotics used to treat urinary tract infections

\section{Discussion:}

TI is particularly common in women and girls. The present study revealed $57.63 \%$ positive CBEU in women against $42.37 \%$ in men, a female/male sex ratio of 1.36 . Our results were similar to the literature such as a study conducted in the bacteriology laboratory of the University Hospital of Rabat, which showed a prevalence of $54.88 \%$ in women and $44.45 \%$ in men. [4] Another study conducted at the University Hospital of Rabta in Tunisia shows a predominance of women with a female/male sex ratio of 3.15. [6] Another study conducted at the HMIMV of Rabat, over a period of 6 months in the extra-hospital environment in 5 laboratories showed a female predominance of $E$ coli UTIs of $69.3 \%$ against $21.4 \%$ in men. [5]. This female predominance is related to the anatomical configuration: shortness of the urethra, proximity of the genital and anal orifices, inadequate hygiene practices, sexual intercourse and pregnancy; imbalance of the bacterial saprophyte flora of the vagina and urethra secondary to overly scrupulous hygiene (use of soaps that imbalance the usual bacterial flora of the vagina and promote colonization by uropathogenic agents), as well as estrogen-progesterone treatments, which promote theoccurrence of UTIs by altering hormonal status, facilitating the penetration of germs by decreasing urethrovesical sphincter tone $[19,20]$,Age is also involved in the predisposition to urinary tract infections, particularly in women, who undergo several hormonal and anatomical changes during their lives. The age groups most concerned according to our study are: the pediatric population and postmenopausal women. Between 0-15 years of age: UTI in pediatrics is in the order of 0.1 to $1 \%$ in full-term newborns and can reach 3 or $4 \%$ in premature and post-mature newborns. According to the data of our study, in newborns and small infants, UTIs were more frequently found in boys, i.e. a sex ratio of $4 / 1$, with 5 female UTIs and 20 male UTIs. Thus, as the age of the female child increases, UTIs become more frequent. At preschool age, girls are more often infected than boys. By the age of six, 7\% of girls and $2 \%$ of boys have had at least one episode of UTI. Between the ages of 6 and 16, the frequency is $2 \%$ in girls versus $0.1 \%$ in boys. [18]. In the present study, this age group represents $35.9 \%$ of all female UTIs compared to the other age groups, with $81 \%$ of female cases (226) versus $19 \%$ of male cases $(n=53)$.

16-50 years: This age group represents young women of childbearing age or pregnant. In our study, this age group represents $25.5 \%$ of ITUs. This same finding was found in the study conducted at the Hôpitald'instruction des arméesBégin, the Elbeuf study (2010) with a slightly higher rate with a prevalence of 40.8\%.[7] This rate can be explained by 
several factors: the use of estrogen-progestin, frequent sexual intercourse which facilitates the passage of germs normally present in the vagina into the bladder. A history of UTI or recent antibiotic treatment [8]. In particular, the use of spermicidal gel or diaphragm can also modify the $\mathrm{pH}$ and the local microbial environment. [9]

$>50$ years: In our study, $38.5 \%$ of UTIs are contracted during this period, with a peak between 56 and 65 years $(17.89 \%)$. This is in line with the literature data cited in the Elbeuf study with a rate of $(32.1 \%)$ [8]. This rate is mainly due to the ageing of the vesicosphincter system, which causes bladder stasis, which leads to microbial proliferation due to the reduction in the flushing effect, and which is accentuated by the reduction in urine flow due to a decrease in water intake and the reduction in the immune defences of the urinary tract. Hormonal deficiency, the drop in estrogen levels also favors the alkalinization of the vaginal $\mathrm{pH}$ and the loss of Lactobacilli in the vaginal flora, which favors adhesion to the urothelium and the proliferation of germs.

Escherichia coli belongs to the Enterobacteriaceae family and the Escherichia genus. It is the commensal germ of the digestive flora of mammals also called colibacillus and responsible for infections. E.coli infections are of two types: either intestinal, such as infectious diarrhea, or extraintestinal, such as meningitis, bacteremia and urinary tract infections. [10].in our series, the rate of infection by was $72.5 \%$, which is in line with the literature given the high uropathogenic power of this bacterium: Rabat $201462.94 \%$ for the female sex, for both sexes Nouakchott which finds $64.4 \%$ [11], Pasteur Institute of Casablanca with 69\% [13], CHU of Tunis with 72.2\% [12], Marrakech with $60 \%$ [14], Algeria (Guelma) with 60\% [15], Kenitra with $66.5 \%$ [16], Nador with $40.9 \%$ [17].

The comparison of the resistances of the E.coli strain isolated in our series, with other studies made for the female sex do not differ, whose percentages remain approximately the same except that we note that the resistances in the city sector is lower than those of the hospital.[29],

Antibiotic susceptibility studies have shown significant resistance of E. coli strains to all antibiotics tested. Resistance to aminopenicillins (amoxicillin) is the most frequent and this resistance seems to be corrected by the addition of clavulanic acid. This result is similar to other studies.
Amoxicillin has become the least active antibiotic on E. coli. This resistance is acquired and would be the consequence of the selection pressure linked to the abusive consumption of these antibiotics in developing countries. This justifies the fact that aminopenicillins are no longer recommended for the probabilistic treatment of urinarytract infections. Furthermore, the increase in sensitivity to the combination of amoxicillin and clavulanic acid has led us to hypothesize a decrease in the activity of betalactams. This decrease in activity may be due to hyperproduction of penicillinase, or to the inactivation of the inhibition itself. $\mathrm{C} 3 \mathrm{G}$ are on the other hand very active on this bacterium, only $9 \%$ of the strains were producers of extended spectrum beta-lactamases. This rate is close to that recorded at the HMIMV in Rabat [28], (9.4\%), at the HMA in Marrakech[26], and Sfax (9.4\%) [27], and higher than that ofFrance $(2.5 \%)[25]$, .The strains isolated from urine in our study have a higher rate of resistance to Fluoroquinolones than those recorded in France $(4.2 \%)$ [25], however the results described by other studies have been confirmed by our data. Our study also showed a resistance rate of $46 \%$ for the combination Trimethopirim+sulfamethoxazole. The rate of resistance to this molecule varies between $20.1 \%$ (in France)[25], and $63.86 \%$ (in Dakar)[24],High resistance for Nitrofurantoine in the Nouakchott laboratories (38.9\%)[23], while it is very low in the other studies where the rate of resistance varies between $1 \%$ and $5.5 \%$. Whereas in our study this rate is around $1 \%$. However, this molecule is still less used than quinolones, which are now recommended as first-line treatment for acute uncomplicated cystitis in women, including women over 65 years of age who do not have any comorbidityNo strain of E.coli was resistant to Carbapenems in our series, which allows to consider them as the most active molecules on E.coli as it is reported in other publications. Aminoglycosides are also classified among the most active antibiotics on E.coli, where the rate of resistance does not exceed the value of $3.7 \%$ for Amikacin which keep a good activity, while for Gentamycin we have a slight increase in resistance to this antibiotic $(12 \%)$ because of the wide prescription of it in the hospital environment, but overall these percentages are close to those of the studies cited.

\section{Conclusion:}

In order to reduce the emergence of antibiotic 
resistance and the incidence of urinary tract infections in women, it is recommended to follow radical measures and advice established by health professionals, the AFSSAPS and the SPILF [21,22]. This requires radical measures. For example, in the case of any suspected urinary tract infection, it is preferable to perform an CBEU with mandatory antibiotic susceptibility testing. In fact, the antibiogram is above all a tool to help in the therapeutic decision: by categorizing the sensitive, intermediate or resistant bacteria, it guides the antibiotic therapy with predictivity, contributing to a gain in morbi-mortality according to the severity of the bacterial infections concerned. This will avoid the probabilistic or empirical treatment of urinary tract infections responsible for resistance. Similarly, self-medication should be avoided by controlling the supply of antibiotics at the community and hospital levels. Standard and special hygiene precautions should also be followed in the case of beta-lactamase producing strains. Awareness of health authorities, health professionals and the population is necessary to ensure that these measures are understood and respected.

\section{Abbreviations:}

UTI: Urinary tract infections;

CBEU: Cytobacteriological examination of urine; REMIC: Medical microbiology reference; EUCAST: European Committee on Antimicrobial Susceptibility Testing; ESBL: Extended-spectrum beta-lactamase.

SPILF: The French Society of Infectious Pathology AFSSAPS:french agency for the sanitary safety of health products.

\section{Declarations}

Ethics approval and consent to participate

The study was conducted on anonymous biological samples. It does not concern any personal data that could directly or indirectly identify a specific person.

\section{Consent for publication}

Not applicable.

\section{Availability of data and materials}

All the data and material were presented in the main paper.

\section{Competing interests}

The authors declare that they have no competing interests.

\section{Funding}

No sources of funding were obtained for this project.

\section{Authors' contributions}

All authors have made substantial contributions to all of the following: (1) the conception and design of the study,

(2) drafting the article and revising it critically for important intellectual content, (3) final approval of the version to be submitted.

\section{Acknowledgements:}

None declare

\section{References:}

1. Canis F, Cavallo JD GJ. REMIC. Référentiel een Microbiol médicale. 6éme édition 2018 chapitre 18

2. Chartier E.Infections urinaires (Généralités). Med-Line 2001 ; 2ème edition. page :31-36

3. The European commettee on antimicrobial susceptibility testing (EUCAST). Breakpoint tables for interpretation of MICs and zone diameters. 2016; Versions 6:Available from: http://www.eucast.org.

4. EL HARCH I. Profil bactériologique des infections urinaires diagnostiquées aux différents services du CHU Rabat 2013, n 17 $\mathrm{P}: 47-52$

5. AISSA I. l'HMIMV de rabat Infections urinaires à Escherichia coli : prévalence et évolution de la résistance aux antibiotiques de 2004 à 2008. 2011 n $^{\circ} 139$

6. Larabi K, Étude bactériologique et phénotypes de résistance des germes responsables d'infections urinaires dans un CHU de Tunis : à propos de 1930 cas. Médecine et maladies infectieuses 33 (2003) 348-352

7. Fabre R, Sensibilité aux antibiotiques des Escherichia coli isolés d'infection urinaires communautaires. Médecine et maladies infectieuses 40 (2010) 555-559

8. Lavigne J-P, Quels antibiotiques utiliser en pratique courante dans les infections urinaires communautaires en France .

Spectra Biologie $n^{\circ} 146 \cdot$ Juin 2005

9. Thabet L, Profil bactériologique des infections urinaires chez la femme à l'Hôpital Aziza Othmana : étude à propos de 495 cas, Tunisie(2010); Vol 88 ( $\left.n^{\circ} 012\right)$ : 898 - 901.

10. Bidet P. Facteurs de pathogénécité et 
physiopathologie des Escherichia coli extraintestinaux. Archives de pédiatrie $2012 ; 19$ :S80-S92

11. B. Fatton. Infections urinaires de la femme enceinte. Correspondances en pelvipérinéologie - n ${ }^{\circ}$ 1, vol. IV - janvier/février/mars 2004

12. S. Bonacorsi. Chapitre 16 - Examen cytobactériologique des urines (ECBU). BactériologieMédicale (3e édition) - Techniques Usuelles. 2016, Pages 163-170

13. F. Fourrier, Les modifications physiologiques de la grossesse favorisent-elles la gravité des infections obstétricales Méd Mal Infect. 1994 ; 24, Spécial : 1024-31

\section{I.BENHIBA1}

:Épidémiologie et antibiorésistance des infections urinaires à entérobactérie chez l'adulte dans le CHU de Marrakech et implication thérapeutique.Uro'Andro - Volume $1 \mathrm{~N}^{\circ} 4$ Juillet 2015

15. AA Bentroki,. Résistance aux antibiotiques de souches isolées d'infections urinaires communautaires entre 2007 et 2011 à Guelma (Algérie). Ann Biol Clin 2012 ;70(6) : 666-8 doi:10.1684/abc.2012.0760

16. El. KENZ, Profil de résistance des bactéries aux antibiotiques dans le milieu extra hospitalier dans la ville de Kenitra, thèse N124/2017 »p2628

17. H. Benali, Fréquence et antibiorésistance des germes responsables des infections urinaires à l'hôpital provincial de Nador, thèse N91/2010 ».p :13-14

18. F. Fourrier, Les modifications physiologiques de la grossesse favorisent-elles la gravité des infections obstétricales Méd Mal Infect. 1994 ; 24, Spécial : 1024-31.

19. Wu Spiscitelli . Tracking the evolutionary origin of the méthicillin résistance genes cloning and sequencing of a homologis of mecA from a methicillin susceptible strain of staphylocoque. Microb drug,

Microbial Drug ResistanceVol. 2, N. 4

20. Auval J, Soussy: Antibiogramme. Ed Masson, 4éme édition 1990,7 :188-90

21. Alexander B; CNRS UMB.Mémoire Nouvelles résistances aux antibiotiques 2010 page 3-9
22. Udo Ee, Genetics analysis of community isolates of meticillin-résistant staphylococcus aureus.in western Austria. J Hosp inf 1993 ; 25:97-108

23. N.S.M. Hailaji, La sensibilité aux antibiotiques des bactéries uropathogènes dans la ville de Nouakchott - Mauritanie. Progrès en urologie (2016) 26, 346-352

24. Yacine AMET DIA. Bilan et profil de sensibilité aux antibiotiques des souches bactériennes isolées des infections du tractus urinaire de janvier 2003 à décembre 2013 dans le laboratoire d'analyses de biologie médicale Bio 24 à Dakar (Sénégal)Uro'Andro - Volume $1 \mathrm{~N}^{\circ}$ 4 Juillet 2015

25. F. Bruyèrea, M.. Analyse microbiologique de plus de 600 infections urinaires fébriles prises en charge dans un réseau de soin. Progrèsenurologie (2013) 23, 890-898

26. R.ouardi Le profil bactériologique actuel de l'infection urinaire et l'état de résistance aux antibiotiques au l'hôpital militaire Avicenne de Marrakech 2019.thése de médecine N²17,2017 Marrakech .p32-33.

27. S. Smaouia, Résistance aux antibiotiques des entérobactéries responsables d'infections urinaires communautaires à Sfax (Tunisie). Médecine et maladies infectieuses (2015). Médecine et maladie infectieuse $\mathrm{Vol} 45-\mathrm{N}^{\circ} 8$ août2015.

28. Nezha RACHIDI. Epidémiologie et résistance aux antibiotiques des bactéries isolées d'infection urinaires à l'hôpital militaire d'instruction Mohammed V de rabat. Faculté de médecine et de pharmacie de Rabat, Université Mohammed V, thèse de médecine N59,2014.p25-27

29. WALAA.S Comparaison de la sensibilité aux antibiotiques d'isolats d'Escherichia coli responsable d'infections urinaires féminine en ville et à l'hôpital. Thèse de médecine $\mathrm{N}^{\circ} 58$, 2014 .p17-18 